\title{
Violence and Sex Impair Memory for Television Ads
}

\author{
Brad J. Bushman and Angelica M. Bonacci \\ Iowa State University
}

\begin{abstract}
Participants watched a violent, sexually explicit, or neutral TV program that contained 9 ads. Participants recalled the advertised brands. They also identified the advertised brands from slides of supermarket shelves. The next day, participants were telephoned and asked to recall again the advertised brands. Results showed better memory for people who saw the ads during a neutral program than for people who saw the ads during a violent or sexual program both immediately after exposure and $24 \mathrm{hr}$ later. Violence and sex impaired memory for males and females of all ages, regardless of whether they liked programs containing violence and sex. These results suggest that sponsoring violent and sexually explicit TV programs might not be a profitable venture for advertisers.
\end{abstract}

If your advertising goes unnoticed, everything else is academic. (Bernbach, 1989)

The goal of advertising is to present products or services in an effective manner so individuals will purchase them. Considering that $98 \%$ of American households own at least one television set (Nielsen Media Research, 2001), television commercials would seem an ideal medium to promote goods or services. Advertisers are willing to pay a premium just to air a 30-second ad on television. For example, advertisers paid $\$ 2.3$ million for a single 30-second commercial airing during Super Bowl XXXV. The ad, however, reached more than 130 million potential consumers (McCarthy \& Howard, 2001).

Advertisers seek to promote their products on shows that attract the most viewers especially those between the ages of 18 and 34 years. Although 18- to 34-year-olds watch less television and have less disposable income than do older television viewers, they are highly valued by advertisers. Many advertisers believe that younger viewers are more easily influenced by commercials than are older viewers with more established purchasing habits (Hamilton, 1998).

However, television advertising is effective only if viewers see the commercial. After all, if people do not see a commercial for a particular product, then the advertisement cannot affect their likelihood to buy that product. In turn, even if people do see a commercial, they must at least remember the product advertised and the content of the commercial in order for it to affect purchasing behavior. Thus, advertisers seek to make their commercials memorable to their audience (Harris, 1999).

Brad J. Bushman and Angelica M. Bonacci, Department of Psychology, Iowa State University.

This research was funded by a contract from Paxson Communications Corporation. We thank Veronica Dark for her helpful suggestions on an earlier version of this article; Kevin Kisling, assistant store director, HyVee Supermarket, for allowing us to take color slides of products on the shelves in his store; Valerie Lammers for her assistance with the 24-hr follow-up telephone calls; and Kelli Gardner, Nick Carnagey, Sarah Hilbert, and Misty Skaff for their help taping the programs.

Correspondence concerning this article should be addressed to Brad J. Bushman, Department of Psychology, Iowa State University, Ames, Iowa 50011-3180. E-mail: bushman@iastate.edu

\section{Memory and Commercial Effectiveness}

The usefulness of memory of advertisement to assess advertising effectiveness is debatable (Twyman, 1996). For instance, just because people remember seeing an advertisement does not necessarily mean they will purchase the product. However, memory is a critical component in determining how people respond to advertising, including deciding whether or not to purchase the product. Shimp and Gresham (1983) outlined eight stages of processing advertising. Individuals first must be exposed to the advertisement (Stage 1) and attend to it (Stage 2). Next, they must comprehend the advertising message (Stage 3) and evaluate it in some way, such as favorably or unfavorably (Stage 4). Individuals then encode the message into their long-term memory (Stage 5), so they can retrieve the information at a later time (Stage 6). Once the message is retrieved, individuals decide among the available options, such as what brand to purchase (Stage 7). Finally, they take action based on the decision they made, such as buying the product (Stage 8). Note that some aspect of memory is involved in four of the eight stages (i.e., Stages 1, 2, 5, and 6).

Some evidence suggests that the more individuals are exposed to advertisements for a particular product, the more likely they are to at least consider buying it. Exposure to an advertisement is related to purchasing behavior. For example, in one study, individuals who saw products advertised in a magazine were more likely to consider buying those products than were those who did not see the products in the magazine (Shapiro, MacInnis, \& Heckler, 1997).

Advertising might be effective because it reinforces alreadydeveloped buying habits (Barnard \& Ehrenberg, 1997; Steward, 1992). For a given product, people often purchase one brand over others. Repeated exposure to advertisements of the preferred product reinforces these buying habits. A possible cognitive mechanism to explain such behavior is the availability heuristic (Tversky \& Kahneman, 1973). According to the availability heuristic, individuals make decisions based on the ease with which information comes to mind. Thus, the more exposure individuals have toward something, the more likely it is to come to mind in a decisionmaking situation. With respect to advertising effectiveness, the more an individual is exposed to and remembers advertisements 
for a given product, the more likely that particular product is to come to mind while shopping.

Clearly, being exposed to an advertisement increases its effectiveness. However, individuals see many advertisements, almost 500 per day (Wilson \& Wilson, 1998). Obviously, people do not remember all of them. People might not remember an advertisement either because they did not encode it (encoding failure) or because they encoded it but cannot retrieve it later (retrieval failure).

Individuals might not encode an advertising message, thus failing to transfer it into long-term memory. Encoding failure might occur because individuals did not attend to the advertisement when presented (Stage 1 in Shimp \& Gresham's, 1983, model). Individuals have a limited cognitive capacity and thus cannot attend to all information presented to them. What individuals do attend to depends on several factors, such as how aroused individuals are and how meaningful the information is to them (Kahneman, 1973). Thus, individuals might not attend to an advertisement because their attention is directed elsewhere, such as thinking about the plot of a TV program.

Retrieval failure occurs when individuals do not access information they have encoded into long-term memory (Hunt \& Ellis, 1999). Although there are several explanations for retrieval failure, interference forgetting and cue-dependent forgetting are most relevant to advertising memory. With interference forgetting, individuals cannot retrieve certain information because the information is not reinforced (Hunt \& Ellis, 1999). Similarly, competing information could interfere with commercial memory. For example, a tune played in a commercial might not cue the advertised product because people associate the tune with something else, such as the group who sang it.

Cue-dependent forgetting can also prompt retrieval failure. People might not remember the advertisement because cues present during exposure are not present during retrieval, thus hindering memory. For example, consumers might associate a jingle with a given product. However, they do not hear the jingle during shopping and thus do not remember the advertised product.

\section{Sex, Violence, and Memory}

Retrieval failure alone cannot explain why people do not remember commercials, considering that people see or hear hundreds of advertisements each day. People fail to encode many of the advertisements presented to them. One plausible reason is that individuals are not paying sufficient attention to the advertisement to encode it into long-term memory. For example, there might be contextual characteristics of a TV program that draw attention away from commercials embedded in the show. Two such characteristics are violence and sex.

Individuals have a limited amount of attention to direct toward TV programs (Lang, Newhagen, \& Reeves, 1996). The more attention individuals pay to a TV program, the less attention they have for other stimuli. Thus, the more attentive individuals are toward a TV program, the less attentive capacity they have for the commercials embedded in the program.

Research suggests that individuals pay more attention to TV programs with violent content than to TV programs without violent content (Lang et al., 1996; Williamson, Kosmitzki, \& Kibler, 1995). For example, using a secondary reaction time task, one study found that individuals use more of their attention resources watching a violent news story than a nonviolent one (Lang et al., 1996). Also, individuals remember more information about violent than about nonviolent news clips, suggesting that viewers are paying more attention to the violent news clips (Furnham \& Gunter, 1987; Lang et al., 1996).

Individuals also appear to pay more attention to sexual content than to nonsexual content. For example, individuals pay more attention to sexual stories than nonsexual stories. In one study, reading times were longer for erotic sentences than for neutral sentences (Geer, Judice, \& Jackson, 1994). Also, participants had better memory for erotic and romantic sentences than for neutral sentences (Geer \& McGlone, 1990). Both of these studies suggest that individuals pay more attention to sexual material than to neutral material. Geer and Melton (1997) argued that processing sexual material requires greater cognitive capacity than does processing nonsexual material. Thus, individuals have less cognitive resources to process other stimuli.

\section{Previous Research on the Effect of Televised Violence and Sex on Memory for Ads}

If sexual and violent content occupy attention, then it is possible that viewing sexual or violent TV programs might hinder commercial memory because individuals have less attention to direct toward the commercials. Previous research does suggest that violent or sexual themes might have an adverse effect on memory for commercials. In a meta-analytic review of 12 studies involving 1,772 participants, Bushman and Phillips (2001) found that TV violence impaired memory for ads. The impairment occurred for males and females, for children and adults, and for people who did and who did not like to watch televised violence.

However, we could find no published studies on the effect of televised sex on memory for commercial messages. The main purpose of the current study is to examine whether sexual content in TV programming reduces memory for commercials in the same way that violent programming does.

\section{Violence and Sex on Television}

Although advertisers market their products to people of all ages, many advertisers target 18- to 34-year-old viewers whom they believe to be the most impressionable. However, individuals in this age group watch fewer hours of television than do older viewers (Hamilton, 1998). Thus, advertisers want to promote their products on shows that younger viewers do watch. Programs that contain sex and violence typically attract younger viewers (Hamilton, 1998; Parent's Television Council, 1999). In fact, stations that market to the 18- to 34-year-old demographic, such as the Warner Brothers Network, air programs with high amounts of sexual and violent content (Parent's Television Council, 1999).

Overall, television programs frequently contain sexual and violent content. A content analysis showed that about $60 \%$ of TV programs contain violence (Center for Communication and Social Policy, University of California, Santa Barbara, 1998). The results are similar for sex; a majority of TV programs (56\%) contain sex (Kunkel et al., 1999).

Although programs with violent and sexual content attract younger viewers, overall they attract fewer viewers than programs 
without violence and sex, thus reducing the impact of the advertisement (Hamilton, 1998; Parent's Television Council, 1999). The impact of the advertisement would be further reduced if viewers of the TV program could not remember the product being advertised. The current study seeks to demonstrate that watching a TV program with sexual or violent content will reduce memory for commercials.

\section{Overview}

Participants were randomly assigned to watch a violent, sexually explicit, or neutral TV program. Each program contained nine ads for products with broad market appeal (e.g., soda pop, cereal, laundry detergent). Immediately after viewing the TV program, participants recalled the advertised brands. They also identified the advertised brands from color slides of brands on supermarket shelves. The next day an experimenter telephoned participants and again asked them to recall the advertised brands. We anticipated poorer memory for commercial messages among participants who watched a violent or sexual TV program than among those who watched a neutral TV program because we expected violence and sex to interfere with their ability to process the commercial messages.

\section{Method}

\section{Participants}

Participants were 328 adults ( 165 men, 163 women) between the ages of 18 and 54 years. Two participants, a Baptist minister and his wife, were offended by the sexually explicit TV program they saw ("The Man Show") and left the experiment early. Data from 2 other men were also discarded. One became angry (for no apparent reason), and the other could not read. Both men saw "Encounters With the Unexplained." Thus, the final sample consisted of 324 adults (162 men, 162 women). There were 108 participants (54 men, 54 women) in each of the three treatment groups (i.e., violent, sexually explicit, or neutral television program).

The age distribution of participants was representative of that of adults the same age in the U.S. households with TVs (i.e., 17\%, age 18-24 years; $12 \%$, age $25-29$ years; $14 \%$, age $30-34$ years; $15 \%$, age $35-39$ years; $16 \%$, age $40-44$ years; $14 \%$, age $45-49$ years; $13 \%$, age $50-54$ years; Nielsen Media Research, 2000). These age groups represent about $72 \%$ of the adult population in U.S. households with TVs (Nielsen Media Research, 2000). About $90 \%$ of participants were White.

Participants were recruited using newspaper advertisements. They received \$25 in exchange for their voluntary participation.

\section{Procedure}

Participants were tested in small groups $(n s=1-15)$, but each worked independently on all tasks. They were told that the researchers were studying attitudes toward TV programs. The sessions were conducted in a comfortable setting. Participants were seated in padded chairs and were given soft drinks and cookies.

After giving their informed consent, participants were randomly assigned to watch a violent, sexually explicit, or neutral television program. To ensure that we adequately sampled the program types, we used six exemplars of each program type (Wells \& Windschitl, 1999). A die was rolled to determine the program that was shown. The six violent programs were "La Femme Nikita," "Martial Law," "Toughman," "World Wrestling Federation Monday Night Nitro," "Tour of Duty," and "Millennium." All of the violent programs had a violent content code (V); none had a sex content code (S). The six sexually explicit programs were "Strip Poker,"
"X-Show," "Howard Stern," "Son of the Beach," "Man Show," and "Strip Mall." All of the sexual programs had a sex content code (S); none had a violent content code $(\mathrm{V})$. The six neutral programs were "Encounters with the Unexplained," "It's a Miracle," "Mysterious Ways," "Miracle Pets," "Candid Camera," and "Doc." The neutral programs were recorded from the PAX channel. None of the neutral programs had violent $(\mathrm{V})$ or sex $(\mathrm{S})$ content codes. All programs were 40 to $45 \mathrm{~min}$ long and were taped from cable television channels.

The commercials originally embedded in the program were edited out. The same nine 30-s commercial messages were then embedded in each TV program. The commercials were for products with broad market appeal (e.g., soft drinks, snacks, cereal, laundry detergent). There were three commercial breaks at approximately $12 \mathrm{~min}, 24 \mathrm{~min}$, and $36 \mathrm{~min}$ into each program and three commercials in each break. The order in which the commercials were shown was randomized.

Immediately after viewing the videotape, participants rated how exciting, boring, involving, violent, and sexually arousing they thought the TV program was. The ratings were made along a 10-point scale ranging from 1 (not at all) to 10 (extremely). The exciting, boring, and involving ratings were used to control for differences among programs other than violent and sexual content. Violence ratings were expected to be higher for violent programs than for sexual and neutral programs. Sexually arousing ratings were expected to be higher for sexual programs than for violent and neutral programs.

After viewing the TV program, participants were given a surprise free-recall test. They were told to recall the brand names in the commercial messages.

A brand-choice decision made in a store might need only a recognition level of learning because the choices can be reviewed at the time a purchase decision is made (Singh \& Rothschild, 1983). Even when a consumer makes a shopping list of products in the home, the final brand selection generally occurs in the store (Bettman, 1979). Thus, we also included a surprise recognition test. For the recognition test, we took color slides of products on supermarket shelves. For each product (e.g., laundry detergent), participants saw four brands: the advertised brand and three foil brands. For each type of product, participants identified which of the four brands was shown in the ad. The order of products and the order of brands within each product were randomized for each experimental session. The slides were shown at the rate of one slide every $5 \mathrm{~s}$.

After completing the surprise memory tests, participants reported the number of hours each week they spent watching TV and the percentage of time they spent watching programs containing violence and sex. These measures were taken to control for habitual exposure to televised violence and sex. To control for previous exposure to the TV programs and commercial messages, we also asked participants whether they had seen the TV program and any of the ads before.

The next day (i.e., $24 \mathrm{hr}$ later), participants were contacted by telephone and were again asked to recall the names of the nine brands in the advertisements. The researcher who called participants did not know what TV program they saw. We were able to recontact 310 of the 324 participants, for a response rate of $96 \%$. Finally, individuals were fully debriefed and were thanked for their participation.

\section{Results}

\section{Preliminary Analyses}

Violence ratings. As expected, there was a significant effect for type of TV program on violence ratings, $F(2,321)=114.86$, $p<.05, M S E=4.99$ (Table 1$)$. Violence ratings were higher for violent programs than for sexual and neutral programs, $t(321)=12.33, p<.05, r_{\mathrm{pb}}=.57$ and $t(321)=13.77, p<.05$, $r_{\mathrm{pb}}=.61$, respectively. Violence ratings did not differ for the latter two groups, $t(321)=1.52, p>.05, r_{\mathrm{pb}}=.08$. 
Table 1

Check of Violent and Sexual Content of Different

Types of Programs

\begin{tabular}{llll}
\hline & \multicolumn{3}{c}{ Program type } \\
\cline { 2 - 4 } Rating dimension & Violent & Sexual & Neutral \\
\hline Violent & & & \\
$\quad M$ & $6.34_{\mathrm{a}}$ & $2.61_{\mathrm{b}}$ & $2.14_{\mathrm{b}}$ \\
$\quad S E$ & 0.21 & 0.21 & 0.22 \\
Sexually arousing & & & \\
$M$ & $2.06_{\mathrm{b}}$ & $3.58_{\mathrm{a}}$ & $1.16_{\mathrm{c}}$ \\
$S E$ & 0.17 & 0.17 & 0.17 \\
\hline
\end{tabular}

Note. $n=108$ participants per group. Scores could range from 1 (not at all) to 10 (extremely). Subscripts refer to within-row comparisons. Means sharing the same subscript are not significantly different at the .05 level.

Sexually arousing ratings. As expected, there was a significant effect for type of TV program on sexually arousing ratings, $F(2,321)=51.34, p<.05, M S E=3.13$ (see Table 1). Sexual arousal ratings were higher for sexual programs than for violent or neutral programs, $t(321)=6.31, p<.05, r_{\mathrm{pb}}=.33$ and $t(321)=10.01, p<.05, r_{\mathrm{pb}}=.49$, respectively. Sexual arousal ratings were also higher for violent programs than for neutral programs, $t(321)=3.74, p<.05, r_{\mathrm{pb}}=.20$. There was a small amount of sexual content in some of the violent programs. For example, in "Millennium," a man and woman are killed while they are in bed. In "World Wrestling Federation Monday Night Nitro," there is a female wrestler in a bikini. There was no sexual content in any of the neutral programs.

Differences among exemplars of different types of TV programs. To increase the generalizability of findings, we included six exemplars of each type of TV program. There were no significant differences among the six violent programs, among the six sexual programs, and among the six nonviolent programs on any of the memory measures (i.e., immediate free recall and recognition, delayed free recall; $p s>.05)$. The random-effects variance estimates for program exemplar were also quite small, ranging from 0.000 to $0.132(M=0.035)$. None of the random-effects variance estimates significantly differed from zero $(p s>.05)$. Thus, the data were collapsed across exemplars of program types for subsequent analyses.

Demographic differences. There were no main effects or interactions for any of the demographic variables (i.e., sex, age, race) on any of the memory measures $(p s>.05)$. Thus, the data were collapsed across sex, age, and race for subsequent analyses.

\section{Primary Analyses}

Three measures were used to assess memory for commercial messages (i.e., immediate free recall and recognition and delayed free recall). The three memory measures were significantly correlated. ${ }^{1}$ Multivariate analysis of covariance was, therefore, used to test the effects of television violence on the three memory measures simultaneously. Covariates included whether participants had seen the TV program and commercials before, ratings of how exciting, boring, and involving the TV program was, hours spent watching television per week, habitual exposure to televised sex and violence, and number of hours between the experiment and the delayed recall test.

The MANCOVA found a significant effect for type of program on memory scores, Wilks's $\lambda=.81, F(6,592)=11.15, p<.05$. As expected, memory for ads was lower for people who saw a violent or sexual TV program than for those who saw a neutral TV program, Wilks's $\lambda=.82, F(3,191)=13.90, p<.05$, and .77 , $F(3,196)=19.99, p<.05$, respectively. Memory for ads did not differ for people who saw the violent and sexual programs, Wilks's $\lambda=.97, F(3,194)=1.83, p>.05$.

Univariate analysis of covariance was used to test the effects of televised violence and sex on each memory measure separately (Johnson \& Wichern, 1998). The analyses met the homogeneity of slopes assumption (i.e., program type did not interact with any of the covariates to influence any of the memory measures). For each dependent variable, the pooled mean square error was used for all significance tests.

Immediate free-recall test. Type of program significantly influenced free recall of brands immediately after exposure to the TV program, $F(2,313)=15.71, p<.05, M S E=3.01$ (Table 2). As expected, brand recall was greater for participants who saw a neutral program than for those who saw a violent or sexual program, $t(313)=4.29, p<.05, r_{\mathrm{pb}}=.24$ and $t(313)=5.39, p<$ $.05, r_{\mathrm{pb}}=.29$, respectively. Brand recall did not differ for participants who saw the violent and sexual programs, $t(313)=1.53, p$ $>.05, r_{\mathrm{pb}}=.09$.

Immediate recall was also positively correlated with the number of ads participants had seen before, $F(1,313)=28.82, p<.05$, $r=.28$. No other covariates were significant.

Immediate recognition test. Type of program significantly influenced recognition of brands immediately after exposure to the TV program, $F(2,313)=13.25, p<.05, M S E=3.85($ Table 2$){ }^{2}$ As expected, brand recognition was greater for participants who saw a neutral program than for those who saw a violent or sexual program, $t(313)=3.57, p<.05, r_{\mathrm{pb}}=.20$ and $t(313)=5.07, p<$ $.05, r_{\mathrm{pb}}=.28$, respectively. Brand recognition did not differ for participants who saw the violent and sexual programs, $t(313)=1.91, p>.05, r_{\mathrm{pb}}=.11$.

Immediate recognition was also positively correlated with the number of ads participants had seen before, $F(1,313)=19.82$, $p<.05, r=.24$. No other covariates were significant.

Delayed free-recall test. Type of program significantly influenced free recall of brands $24 \mathrm{hr}$ after exposure to the TV program, $F(2,298)=31.84, p<.0001, M S E=2.64$ (see Table 3). As expected, delayed brand recall was greater for participants who saw a neutral program than for those who saw a violent or sexual program, $t(298)=6.70, p<.05, r_{\mathrm{pb}}=.36$ and $t(298)=7.33, p<$ $.05, r_{\mathrm{pb}}=.39$, respectively. Delayed brand recall did not differ for participants who saw the violent and sexual programs, $t(298)$ $=1.09, p>.05, r_{\mathrm{pb}}=06$.

\footnotetext{
${ }^{1}$ The correlations were .57 between immediate brand recall and immediate brand recognition; .69 between immediate brand recall and delayed (24-hr) recall; and .64 between immediate brand recognition and delayed (24-hr) recall (all $p$ s $<.05$ ).

${ }^{2}$ The effect of program content on immediate brand recognition remains significant even after controlling for immediate brand recall, $F(1$, $312)=3.55, p<.05$.
} 
Table 2

Effects of Violence and Sex on Memory for

Commercial Messages

\begin{tabular}{|c|c|c|c|}
\hline \multirow[b]{2}{*}{ Memory measure } & \multicolumn{3}{|c|}{ Program type } \\
\hline & Violent & Sexual & Neutral \\
\hline \multicolumn{4}{|l|}{ Immediate brand recall } \\
\hline \multicolumn{4}{|l|}{ Unadjusted } \\
\hline$M$ & $2.08_{\mathrm{b}}$ & $1.71_{\mathrm{b}}$ & $3.17_{\mathrm{a}}$ \\
\hline$S E$ & $0.18^{\circ}$ & $0.17^{\circ}$ & $0.17^{\circ}$ \\
\hline \multicolumn{4}{|l|}{ Adjusted } \\
\hline M & $2.09_{\mathrm{b}}$ & $1.72_{\mathrm{b}}$ & $3.15_{\mathrm{a}}$ \\
\hline$S E$ & $0.17^{\circ}$ & 0.18 & $0.18^{\circ}$ \\
\hline \multicolumn{4}{|c|}{ Immediate brand recognition } \\
\hline \multicolumn{4}{|c|}{ Unadjusted } \\
\hline$M$ & $6.48_{\mathrm{b}}$ & $5.93_{\mathrm{b}}$ & $7.45_{\mathrm{a}}-\mathrm{c}-\mathrm{a}$ \\
\hline$S E$ & 0.21 & 0.22 & 0.15 \\
\hline \multicolumn{4}{|l|}{ Adjusted } \\
\hline M & $6.46_{\mathrm{b}}$ & $5.94_{b}$ & $7.46_{\mathrm{a}}$ \\
\hline$S E$ & 0.19 & $0.20^{\circ}$ & 0.20 \\
\hline \multicolumn{4}{|c|}{ Delayed (24-hr) brand recall } \\
\hline \multicolumn{4}{|c|}{ Unadjusted } \\
\hline$M$ & $3.02_{\mathrm{b}}$ & $2.72_{\mathrm{b}}$ & $4.65_{\mathrm{a}}-\mathrm{c}-\mathrm{c}$ \\
\hline$S E$ & 0.16 & 0.18 & 0.16 \\
\hline \multicolumn{4}{|l|}{ Adjusted } \\
\hline M & $3.01_{\mathrm{b}}$ & $2.76_{\mathrm{b}}$ & $4.61_{\mathrm{a}}$ \\
\hline$S E$ & 0.16 & 0.17 & 0.17 \\
\hline
\end{tabular}

Note. For the immediate memory measures, there were $n=108$ participants in each group. For the delayed memory measure, the $n$ s were 101, 106, and 103 for the violent, sexual, and neutral groups, respectively. Scores could range from 9 (all brands remembered) to 0 (no brands remembered). Unadjusted means were not adjusted for any covariates. Adjusted means were adjusted for covariates. Covariates included whether participants had seen the TV program and commercials before; exciting, boring, and involving ratings for the TV program; hours spent watching TV per week; and habitual exposure to televised sex and violence. The delayed-recall analysis also included the number of hours between the experiment and the delayed-recall test as a covariate. Subscripts refer to within-row comparisons. Means sharing the same subscript are not significantly different at the .05 level.

Some of the covariates were also significant. Delayed recall was positively correlated with the number of ads participants had seen before and was negatively correlated with the length of the delay between exposure to the ads and the recall test, $F(1,298)=17.77$, $p<.05, r=.23$ and $F(1,298)=5.37, p<.05, r=-.15$, respectively.

\section{Discussion}

Violence and sex are often used to draw viewers to TV programs, but they might interfere with memory for the ads embedded in those programs. The current study showed that televised violence and sex impaired memory for commercial messages immediately after exposure and even $24 \mathrm{hr}$ later. The effect of televised violence and sex on memory for commercial messages was quite robust. The memory impairment occurred for both men and women, for adults ranging in age from 18 to 54 years (representing more than $70 \%$ of adult TV viewers), and for people who like and who do not like to watch violence and sex on television.

These findings are consistent with the meta-analytic findings reported by Bushman and Phillips (2001) for violent TV programs.
However, these findings do more than replicate previous findings. To date, no study has examined the effect of televised sex on memory for commercial messages. Like violence, sex impairs memory for commercial messages. One possible reason why sex and violence impair memory for commercials is because people pay attention to sex and violence, thus reducing the amount of attention they can direct toward other stimuli, such as commercials.

\section{Commercial Memory and Attentive Capacity}

Because people have a limited amount of attention, they cannot attend to all stimuli presented to them (Kahneman, 1973; Lang et al., 1996). The more attention people direct toward the television show, the less attentive capacity they have for other stimuli, including the commercials embedded in the program. If individuals pay less attention to the commercials, then they should have poorer memory for them because they failed to encode the commercial message into long-term memory. In the current study, participants had poorer memory for commercials after watching a program with sexual or violent content than a neutral program. Although we did not measure attention per se, these results suggest that individuals attend more to sexual and violent content than to neutral content, thus limiting the amount of attentive capacity they can direct toward the commercials.

One possible explanation why commercial memory was better for neutral programs than sexual or violent programs is that sexual and violent programs are more interesting and involving than neutral programs. Indeed, previous research suggests that commercial memory is negatively correlated with how interesting and involving the TV program is (Norris \& Colman, 1993; Soldow \& Principe, 1981). However, in the current study, we statistically controlled for how interesting and involving the TV program was. Thus, the memory impairment that occurred cannot be attributed to differences in how exciting, boring, and involving the TV programs were.

Also, we controlled for other important factors that might influence memory for ads (i.e., whether they had seen the TV program before, the number of ads they had seen before, hours spent viewing television, and habitual exposure to televised sex and violence). To increase the generalizability of findings, we also included six exemplars of each type of program. Thus, it appears that the memory impairment was due to violent and sexual content rather than to some other difference among the TV programs.

We have suggested that memory for commercials might be impaired after watching violent or sexual programming because people pay more attention to sexual and violent content than to neutral content. This would limit the attention they could direct toward the commercials. Another possibility is that sexual and violent content prompt sexual and violent thoughts. Thinking about sex and violence, instead of the commercials, could reduce commercial memory.

\section{Cognitive Neoassociation Theory}

These results are consistent with Berkowitz's (1984) cognitive neoassociation theory. According to Berkowitz, "The aggressive ideas suggested by a violent movie can prime other semantically related thoughts, heightening the chances that viewers will have other aggressive ideas in this period" (p. 411). Thus, scenes of 
violence on television might cause viewers to think about other aggressive ideas rather than about the commercial messages. The same could be true of sex: Sexual scenes on television might cause viewers to think about sex rather than about the commercial messages.

We have already suggested that sexual and violent content might capture more attention then neutral content, thus limiting the amount of attention one can direct toward the commercials. This alone would reduce the impact of the commercial message. However, if sexual and violent content also prompt sexual and violent thoughts, this would further reduce the impact of the advertisement. If viewers are thinking about the violence and sex they have just seen on the screen, they will be less likely to think about the commercial messages.

\section{Impact of Sexual and Violent Content on Commercial Memory}

How large is the effect of televised violence and sex on memory impairment for commercial messages? We used multivariate metaanalytic procedures to combine the correlations from the three memory measures (see Wang \& Bushman, 1999). Across the three memory measures, the average correlation was -.27 for violence and -.32 for sex. The magnitude of the effect did not differ for violence and sex; both types of programming impaired memory for ads. These correlations are moderate in size (Cohen, 1988).

Bushman and Phillips (2001) conducted a meta-analysis on the effect of televised violence on memory for commercial messages. The average correlation for the 12 studies in their meta-analysis was -.186 , with a $95 \%$ confidence interval ranging from -.231 to -.139 . We used Tukey's (1977) box plot to determine whether the correlations we observed for violent TV programs in this study were outliers in comparison to those included in the Bushman and Phillips meta-analysis. The correlations in the current study were not identified as outliers. If the current study is included in the Bushman and Phillips meta-analysis, the results do not change much at all. The average correlation for the 13 studies is -.189 , with a $95 \%$ confidence interval ranging from -.231 to -.145 .

\section{Limitations and Future Research}

Previous research suggests that televised violence reduces memory for commercials (Bushman \& Philips, 2001). The results of this study suggest that televised sex also reduces commercial memory. We offer two potential explanations as to why sexual and violent content might reduce commercial memory. First, sexual and violent content capture attention, thus limiting the amount of attention people can direct toward commercials. Because they do not attend to the commercials, memory for them is reduced. Second, consistent with cognitive neoassociation theory, sexual and violent content prompt related sexual and violent thought. Thus, individuals are thinking about sex and violence, not about the commercials.

However, the results of the current study and our explanation for the effects must be interpreted with caution. This study is exploratory. We sought to determine whether sexual TV content reduces memory for commercials as violent content does. Although our prediction was confirmed, we cannot say definitively what is driving the effect. We do know that the effect did not occur because sexual and violent TV programming is more interesting and involving, because we statistically controlled for these factors. However, future research should focus on the underlying cognitive mediators to discern the nature of the relationship between program content and commercial memory.

We suggest that sex and violence impair commercial memory because they consume attention and prompt sexual and violent thoughts, thus reducing the likelihood that the commercial message is encoded into long-term memory. However, we did not include measures to test such suppositions. Future research should include measures to assess how sexual and violent content affect attention and sexual and violent thoughts. For example, completing a secondary reaction time task immediately after viewing the TV program could demonstrate whether sexual and violent program content consume more attention then neutral program content. To test predictions derived from cognitive neoassociation theory, participants could complete implicit memory measures assessing whether sexual and violent program content prompt related thoughts.

We did not include any measures of arousal or affect in the current study. Both arousal and affect could affect commercial memory. For example, Bushman (1998) found that angry affect served as a mediator between the relationship of viewing a violent TV program and decreased commercial memory. In addition, research suggests that viewing a violent news story generates arousal and negative emotions (Lang et al., 1996). Arousal and negative emotions could prompt retrospective disruption for commercials embedded in the programs (Newhagen, 1998). Angry affect, arousal, and negative emotions could impair commercial memory after viewing a violent TV program. Sexual programming might also increase arousal and negative emotions if the material is perceived as offensive. Future research should include both measures of arousal and affect to test such possibilities.

Any suppositions we make about encoding or retrieval failure are speculative. The design of the study does not allow us to discriminate whether the memory deficit is due to encoding or retrieval failure. Future research should focus on this issue.

Also, including all three memory measures in one study might be problematic. Any prior testing likely influences subsequent testing. For example, in the current study, 24-hr recall was better than immediate recall. The simplest explanation for the improvement between immediate and 24-hr recall is that the slide recognition memory test prompted participants to remember some of the commercials they initially forgot. Future research might consider treating type of memory test as a between-subjects factor.

Another limitation of the current study is that we did not manipulate the content of the commercials. There was no sexual or violent content in any of the commercials. Individuals might have had poorer memory for commercials after watching a sexual or violent program because the content of the commercials was inconsistent with the content of the TV program. Research has shown that individuals remember related information better than unrelated information (Hunt \& Ellis, 1999). Thus, it is possible that individuals might have better commercial memory if the content of the commercial is similar to the content of the TV program. For example, participants might have good recall of commercials sexual in nature if they watched a program with sexual content compared with a program with violent or neutral content. Future 
research should manipulate not only the content of the TV program but also the content of commercials.

\section{Conclusion}

Research from hundreds of studies conducted over several decades has shown that televised violence causes an increase in societal violence (see Bushman \& Huesmann, 2001, for a review). Far less research has been conducted on the effect of televised sex on sexual behavior. However, there is an emerging literature demonstrating that sexually explicit media promote sexual callousness, cynical attitudes about love and marriage, and perceptions that promiscuity is the norm (Allen, Emmers, \& Gebhardt, 1995; Zillmann, 2000). Moreover, media in which sex is combined with violence may have particularly pernicious effects (e.g., Allen, D’Alessio, \& Brezgel, 1995; Linz, Donnerstein, \& Penrod, 1988). Thus, televised violence and sex can have harmful effects on society.

It is unlikely that moral appeals from parents and other concerned citizens will influence the TV industry to reduce the amount of violence and sex on television. The bottom lineprofits - actually determines what programs are shown on television. If advertisers refused to sponsor them, violent and sexually explicit TV programs would become extinct. According to former CBS programming chief Jeff Sagansky, "The number one priority in television is not to transmit quality programming to viewers, but to deliver consumers to advertisers." (Kim, 1994, p. 1434). The current findings suggest that advertisers should think twice about sponsoring violent and sexually explicit TV programs.

\section{References}

Allen, M., D’Alessio, D., \& Brezgel, K. A. (1995). A meta-analysis summarizing the effects of pornography. II: Aggression after exposure. Human Communication Research, 22, 258-283.

Allen, M., Emmers, T., \& Gebhardt, L. (1995). Exposure to pornography and acceptance of the rape myths. Journal of Communication, 45, 5-26.

Barnard, N., \& Ehrenberg, A. (1997). Advertising: Strongly persuasive or nudging? Journal of Advertising Research, 15, 21-31.

Berkowitz, L. (1984). Some effects of thoughts on anti-social and prosocial influences of media effects: A cognitive-neoassociation analysis. Psychological Bulletin, 95, 410-427.

Bernbach, W. (1989). Bill Bernbach said. New York: DDB Needham Worldwide.

Bettman, J. R. (1979). Memory factors in consumer choices: A review. Journal of Marketing, 43, 37-53.

Bushman, B. J. (1998). Effects of television violence on memory for commercial messages. Journal of Experimental Psychology: Applied, 4, 291-307.

Bushman, B. J., \& Huesmann, L. R. (2001). Effects of televised violence on aggression. In D. G. Singer \& J. L. Singer (Eds.), Handbook of children and the media (pp. 223-254). Newbury Park, CA: Sage.

Bushman, B. J., \& Phillips C. M. (2001). If the television program bleeds, memory for the advertisement recedes. Current Directions in Psychological Science, 10, 44-47.

Center for Communication and Social Policy, University of California, Santa Barbara. (1998). National television violence study (Vol. 3). Santa Barbara, CA: Author.

Cohen, J. (1988). Statistical power analysis for the behavioral sciences (2nd ed.). New York: Academic Press.

Furnham, A., \& Gunter, B. (1987). Effects of time of day and medium of presentation on immediate recall of violent and nonviolent news. Applied Cognitive Psychology, 1, 255-262.

Geer, J. H., Judice, S., \& Jackson, S. (1994). Reading times for erotic material: The pause to reflect. The Journal of General Psychology, 121, $345-352$.

Geer, J. H., \& McGlone, M. S. (1990). Sex differences in memory for erotica. Cognition and Emotion, 4, 71-78.

Geer, J. H., \& Melton, J. S. (1997). Sexual content-induced delay with double-entendre words. Archives of Sexual Behavior, 26, 295-316.

Hamilton, J. T. (1998). Television violence and public policy. Ann Arbor: University of Michigan Press.

Harris, R. J. (1999). A cognitive psychology of mass communication (3rd ed.). Mahwah, NJ: Erlbaum.

Hunt, R. R., \& Ellis, H. C. (1999). Fundamentals of cognitive psychology (6th ed.). Dubuque, IA: McGraw-Hill College.

Johnson, R. A., \& Wichern, D. W. (1998). Applied multivariate statistical analysis (4th ed.). Upper Saddle River, NJ: Prentice Hall.

Kahneman, D. (1973). Attention and effort. Englewood Cliffs, NJ: Prentice Hall.

Kim, S. J. (1994). "Viewer discretion is advised": A structural approach to the issue of television violence. University of Pennsylvania Law Review, 142, 1383-1441.

Kunkel, D., Cope, K. M., Maynard Farinola, W. J., Biely, E., Rollin, E., \& Donnerstein, E. (1999). Sex on TV. Menlo Park, CA: Kaiser Family Foundation.

Lang, A., Newhagen, J., \& Reeves, B. (1996). Negative video as structure: Emotion, attention, capacity, and memory. Journal of Broadcasting and Electronic Media, 40, 460-477.

Linz, D. G., Donnerstein, E., \& Penrod, S. (1988). Effects of long-term exposure to violent and sexually degrading depictions of women. Journal of Personality and Social Psychology, 55, 758-768.

McCarthy, M., \& Howard, T. (2001, January 8). Big-name marketers return to line-up. USA Today, p. B1.

Newhagen, J. E. (1998). TV news images that induce anger, fear, and disgust: Effects on approach-avoidance and memory. Journal of Broadcasting \& Electronic Media, 42, 265-276.

Nielsen Media Research. (2000). Nielsen television index, national audience demographics (Vol. 1). New York: Author.

Nielsen Media Research. (2001). Galaxy explorer. New York: Author.

Norris, C. E., \& Colman, A. M. (1993). Context effects on memory for television advertisements. Social Behavior and Personality, 21, 279296.

Parent's Television Council. (1999). What a difference a decade makes: A comparison of prime time sex, language, and violence in 1989 and '99. Retrieved April 1, 2002, from http://www.parentstv.org/publications/ reports/Decadestudy/decadecover.html

Shapiro, S., MacInnis, D. J., \& Heckler, S. E. (1997). The effects of incidental ad exposure on the formation of consideration sets. Journal of Consumer Research, 24, 96-104.

Shimp, T. A., \& Gresham, L. G. (1983). An information processing perspective of recent advertising. Current Issues and Research in Advertising, 9, 36-79.

Singh, S. N., \& Rothschild, M. L. (1983). Recognition as a measure of learning from television commercials. Journal of Marketing Research, 20, 235-248.

Soldow, G. F., \& Principe, V. (1981). Responses to commercials as a function of program context. Journal of Advertising Research, 21, 5965 .

Steward, D. W. (1992). Speculation on the future of advertising research. Journal of Advertising, 12, 1-18.

Tukey, J. W. (1977). Exploratory data analysis. Reading, MA: AddisonWesley.

Tversky, A., \& Kahneman, D. (1973). Availability: A heuristic for judging frequency and probability. Cognitive Psychology, 5, 207-302. 
Twyman, T. (1996). Designing advertising research for marketing decisions. Journal of the Market Research Society, 38, 525-548.

Wang, M. C., \& Bushman, B. J. (1999). Integrating results through meta-analytic review using SAS software. Cary, NC: SAS Institute.

Wells, G. L., \& Windschitl, P. D. (1999). Stimulus sampling and social psychological experimentation. Personality and Social Psychology Bulletin, 25, 1115-1125.

Williamson, S. S., Kosmitzki, C., \& Kibler, J. L. (1995). The effects of viewing violence on attention in women. The Journal of Psychology, 129, 717-721.
Wilson, J. R., \& Wilson, S. L. R. (1998). Mass media/mass culture (4th ed.). New York: McGraw-Hill.

Zillmann, D. (2000). Influence of unrestrained access to erotica on adolescents' and young adults' dispositions toward sexuality. Journal of Adolescent Health, 27S, 41-44.

Received May 4, 2001

Revision received October 15, 2001

Accepted October 17, 2001

\section{Low Publication Prices for APA Members and Affiliates}

Keeping you up-to-date. All APA Fellows, Members, Associates, and Student Affiliates receive-as part of their annual dues-subscriptions to the American Psychologist and APA Monitor. High School Teacher and International Affiliates receive subscriptions to the APA Monitor, and they may subscribe to the American Psychologist at a significantly reduced rate. In addition, all Members and Student Affiliates are eligible for savings of up to $60 \%$ (plus a journal credit) on all other APA journals, as well as significant discounts on subscriptions from cooperating societies and publishers (e.g., the American Association for Counseling and Development, Academic Press, and Human Sciences Press).

Essential resources. APA members and affiliates receive special rates for purchases of APA books, including the Publication Manual of the American Psychological Association, and on dozens of new topical books each year.

Other benefits of membership. Membership in APA also provides eligibility for competitive insurance plans, continuing education programs, reduced APA convention fees, and specialty divisions.

More information. Write to American Psychological Association, Membership Services, 750 First Street, NE, Washington, DC 20002-4242. 